\title{
GLOSSOPHARYNGEAL NEURALGIA WITH SYNCOPE AS A SIGN OF NECK CANCER RECURRENCE
}

\author{
Reinaldo Teixeira Ribeiro', Nilton Amorim de Souza², Deusvenir de Souza Carvalho³
}

\begin{abstract}
Glossopharyngeal neuralgia with syncope as a sign of neck cancer is a very rare condition. A review of the literature revealed only 29 cases formerly reported. We present the first Brazilian case of such association. A 68-year-old man presented with paroxysmal excruciating pain over the right side of the neck, sometimes followed by syncope. Given the suspicion of recurrent tumor from a previously treated neck malignancy, a computed tomography scan was performed and a right parapharyngeal tumor was shown. Pain and syncope were successfully controlled with carbamazepine and the patient underwent palliative radiotherapy.

KEY WORDS: glossopharyngeal neuralgia, syncope, neck cancer, recurrence.
\end{abstract}

\begin{abstract}
Neuralgia glossofaríngea com síncope como um sinal de recidiva de câncer do pescoço
RESUMO - Neuralgia glossofaríngea com síncope como um sinal de câncer do pescoço é uma condição muito rara. Uma revisão da literatura revelou apenas 29 casos relatados anteriormente. Apresentamos o primeiro caso brasileiro de tal associação. Um homem de 68 anos se apresentou com dores paroxísticas insuportáveis no lado direito do pescoço, algumas vezes seguidas de síncope. Dada a suspeita de recidiva tumoral derivada de uma malignidade cervical tratada previamente, realizou-se um exame de tomografia computadorizada que evidenciou um tumor parafaríngeo direito. As dores e as síncopes foram controladas satisfatoriamente com carbamazepina e o paciente foi submetido à radioterapia paliativa.
\end{abstract}

PALAVRAS-CHAVE: neuralgia glossofaríngea, síncope, câncer do pescoço, recidiva.

According to the second edition of the International Classification of Headache Disorders', glossopharyngeal neuralgia is a brief severe stabbing pain felt in the ear, base of the tongue, tonsillar fossa or beneath the angle of the jaw. Thus, the pain is located in the distributions of the auricular and pharyngeal branches of the vagus nerve plus of the ipsilateral glossopharyngeal nerve. It is commonly incited by swallowing, talking or coughing and may remit and relapse in the manner of trigeminal neuralgia.

Glossopharyngeal neuralgia was estimated to be 75 times less frequent than trigeminal neuralgia ${ }^{2}$, and its association with syncope was estimated to occur in $1,84 \%$ of the cases ${ }^{3}$. Although generally cryptogenic, this condition sometimes have a demonstrable cause, including neoplasms, infections, inflammations, trauma, elongated styloid process and vascular compression $^{2}$. Glossopharyngeal neuralgia with syncope as a sign of neck tumor is a very rare condition. A fairly diligent review of the literature revealed only 29 cases formerly reported (Table). We present the first Brazilian case of such association.

\section{CASE}

A 68-year-old white man with a history of paralaryngeal and pyriform sinus lymphoepithelioma was treated with radical surgery and radiotherapy about 2 years ago. His tumor was stage $\mathrm{T}_{3} \mathrm{~N} 2 \mathrm{~b}$ Mo and he underwent bilateral neck dissection, right hemithyroidectomy, pharyngolaryngectomy with later reconstruction by means of a free microvascular right thigh flap, and tracheostomy. After surgery, he received radiotherapy with a total 40 Gy to the entire neck.

After a two years follow-up without clinical signs of recurrence or metastasis, the patient presented with paroxysmal excruciating pain over the right side of the neck, sometimes followed by syncope for two weeks. The neck pain was described as a sudden knife attack deep under the right angle of the jaw and over the right posterior area of his mouth, usually provoked by swallowing or protrusion of the tongue, which lasted about 40 seconds. These pain attacks recurred several times along the day, sometimes followed by diaphoresis, cold extremities, pallor, rotatory vertigo, culminating in fainting with fast consciousness recovery. The patient used to become drowsy after the syncopes for a few minutes. At physical examination, no recurrence of the tumor in the neck and pharynx was apparent to the head and neck surgeon, in addition the patient did not have a histo-

'MD, Resident Physician, Department of Neurology, Federal University of São Paulo, São Paulo SP, Brazil; ${ }^{2} \mathrm{MD}$, MSc, Department of Neurology, Federal University of São Paulo, São Paulo SP, Brazil; ${ }^{3} \mathrm{MD}$, PhD, Department of Neurology, Federal University of São Paulo, São Paulo SP, Brazil.

Received 12 July 2007, received in final form 24 August 2007. Accepted 21 September 2007.

Dr. Reinaldo T. Ribeiro - EPMIUNIFESP - Rua Botucatu 740 - 04023-90o São Paulo SP - Brasil. E-mail: reinaldo_ribeiro@yahoo.com.br 


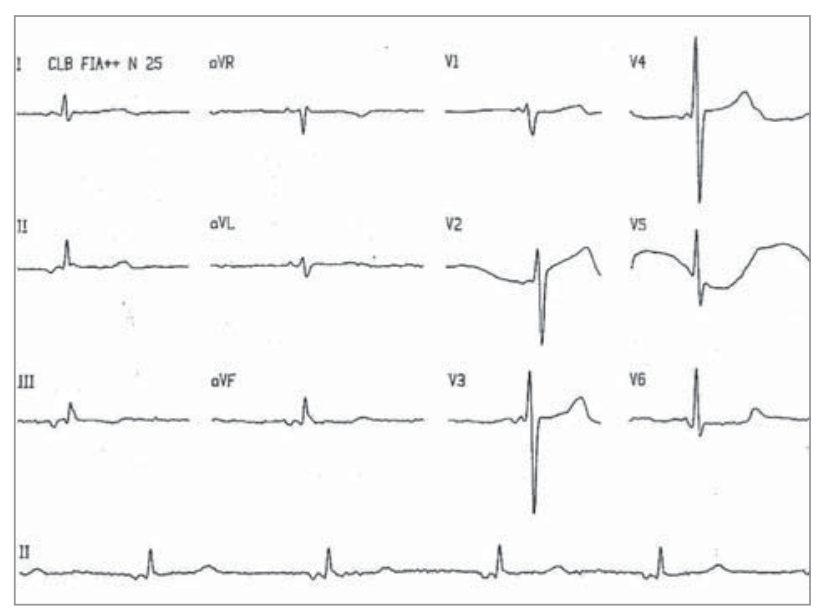

Fig 1. Electrocardiogram showing a temporary bradycardic junctional rhythm after an episode of glossopharyngeal neuralgia with syncope.

ry of syncope or any other cardiovascular disease. However, a typical episode of glossopharyngeal neuralgia with syncope occurred soon after the oral cavity examination had been finished. The patient was immediately referred to the emergency room where he arrived conscious, with 18 respiratory incursions per minute, oxygen digital saturation of $98 \%$ on open air, blood pressure of $110 / 80 \mathrm{mmHg}$ and pulse rate of 50 per minute. Successive electrocardiograms were taken and they showed an initial junctional rhythm, which evolved to a sinusal rhythm without any medical intervention, devoid of any additional symptom or signs of ischemic heart disease (Fig 1).

Witnesses described a tonic posture of the upper limbs prior to the syncope and a subsequent first episode of fecal incontinence, hence the emergency room physician asked for a complete neurological assessment to exclude seizure.

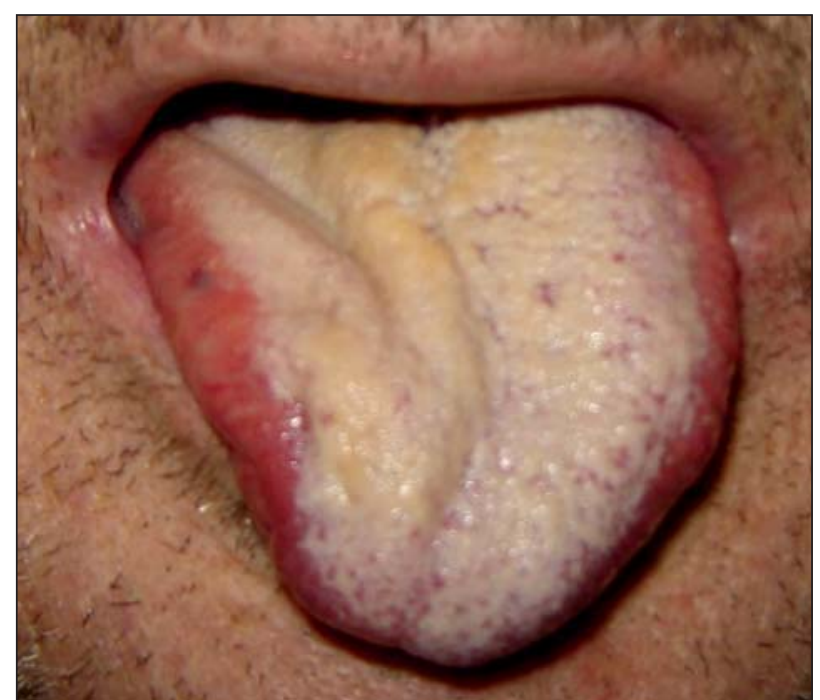

Fig 2. Unilateral atrophy, fasciculations and tongue deviation to the right that were considered to be secondary to right hypoglossal nerve surgical lesion.
Table. Number of reported cases of glossopharyngeal neuralgia with syncope secondary to neck cancer per author(s).

\begin{tabular}{|c|c|}
\hline Author(s) & $\begin{array}{l}\text { Number of } \\
\text { reported cases }\end{array}$ \\
\hline Kollmannsberger et al. ${ }^{15}(1964)$ & 2 \\
\hline Meienberg et al. ${ }^{16}$ (1975) & 1 \\
\hline Roa and Krupin. ${ }^{17}$ (1981) & 1 \\
\hline Dykman et al. ${ }^{12}(1981)$ & 1 \\
\hline Greenberg et al. ${ }^{18}(1981)$ & 1 \\
\hline Sobol et al. ${ }^{19}(1982)$ & 1 \\
\hline Fleischmann et al. ${ }^{20}(1983)$ & 1 \\
\hline Macdonald et al. ${ }^{8}(1983)$ & 2 \\
\hline Kim et al. ${ }^{21}(1985)$ & 1 \\
\hline Weinstein et al. ${ }^{22}$ (1986) & 1 \\
\hline Chalmers and Olson. ${ }^{23}$ (1989) & 2 \\
\hline Papay et al. ${ }^{9}(1989)$ & 3 \\
\hline Pujadas et al." (1990) & 1 \\
\hline Metheetrairut and Brown et al. ${ }^{14}$ (1993) & 1 \\
\hline Tang et al. ${ }^{24}$ (1993) & 1 \\
\hline Rumoroso et al. ${ }^{25}$ (1996) & 1 \\
\hline Carrat et al..$^{26}(1996)$ & 2 \\
\hline Nakahira et al. ${ }^{7}$ (2002) & 2 \\
\hline Nicholls et al. ${ }^{27}$ (2003) & 1 \\
\hline Enguita et al. ${ }^{28}(2003)$ & 1 \\
\hline Garcla et al. ${ }^{29}$ (2003) & 1 \\
\hline Worth et al..$^{\circ}(2005)$ & 1 \\
\hline Ribeiro et al. (current) & 1 \\
\hline
\end{tabular}

Apart from expected post surgical and radiotherapeutic alterations, such as mild weakness of the two trapezius muscles and cervical actinic fibrosis, the remainder neurologic examination only showed a unilateral atrophy, fasciculations and tongue deviation to the right (Fig 2). After protruding the tongue to record its alterations, the patient suffered another glossopharyngeal neuralgia without syn-

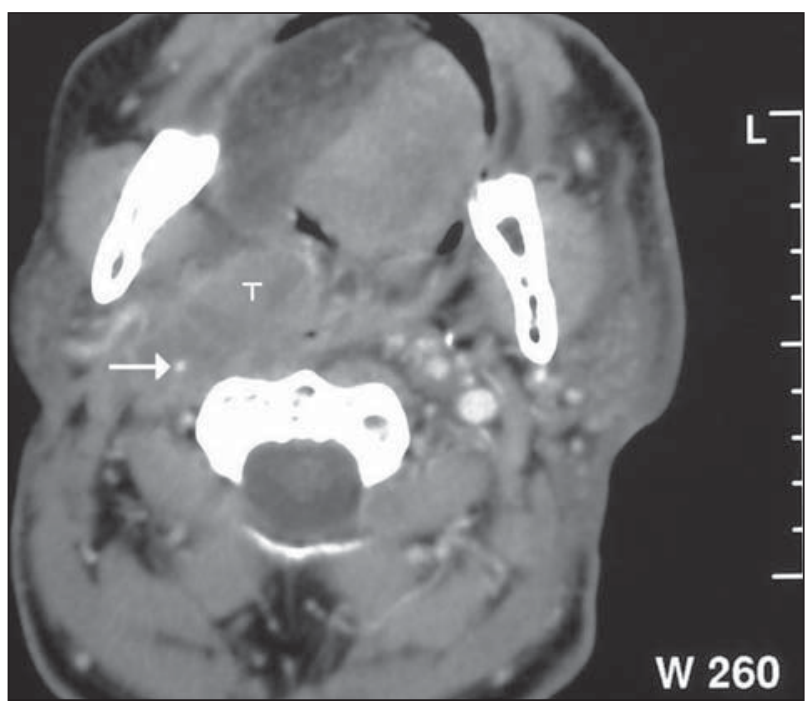

Fig 3. Contrast-enhanced axial computed tomography scan showing right parapharyngeal tumor $(T)$ encasing the right internal carotid artery (arrow) and probably the right 
cope, assuming a tonic posture of the upper limbs due to the intense pain. Despite the unawareness of the patient and family of such pathological changes, the right hypoglossal nerve lesion was supposed to be an accidental consequence of the radical neck surgery. Given the suspicion of recurrent tumor from the previously treated neck malignancy, contrast-enhanced computed tomography scans of the head and neck regions were performed and a right parapharyngeal tumor encasing the right internal carotid artery was shown. Besides, a low-attenuating area on the right half of the tongue that represented denervated muscle atrophy and increased fat after the right hypoglossal nerve lesion was also shown, without intracranial lesions (Fig 3). The diagnosis of symptomatic glossopharyngeal neuralgia with syncope as a sign of neck cancer recurrence was made, treatment with carbamazepine initiated and the patient was referred to head and neck cancer reappraisal.

After a few days of treatment, pain and syncope were successfully controlled with carbamazepine 6oomg daily, enabling the introduction of a nasoenteral tube for nutritional purposes. Carotid sinus massage did not notably cause a decrease in either blood pressure or pulse rate, moreover maneuvers that seemed to trigger the symptoms in the past no longer worked. At the time of writing, the patient had been relieved of glossopharyngeal neuralgia with syncope for about two months and was undergoing palliative radiotherapy.

The patient allowed this report by a written informed consent.

\section{DISCUSSION}

As aforementioned, glossopharyngeal neuralgia alone is a relatively uncommon condition ${ }^{2}$, its association with syncope is considered to be very rare ${ }^{3}$, and this paper reports the thirtieth worldwide case of glossopharyngeal neuralgia with syncope secondary to neck cancer and the first Brazilian case of such association. Among the Brazilian cases of classical glossopharyngeal neuralgia previously reported, four were associated with syncope ${ }^{4-6}$. Likewise, syncope from head and neck cancer is also considered an exceptional event, ranging from $0,33 \%{ }^{7}$ to $0,4 \%^{8}$, however, among those cases, glossopharyngeal neuralgia is a frequent cause of syncope due to head and neck cancer invasion, varying from $11,75 \%^{8}, 50 \%{ }^{7}$, to $60 \%$. These relatively high frequencies emphasize the need of special imaging techniques to uncover occult malignancies of retropharyngeal and parapharyngeal spaces affecting the glossopharyngeal nerve.

Although limited to few reports, glossopharyngeal neuralgia with syncope due to head and neck cancer becomes a matter of urgency in treatment, because of the cardiovascular complications and advanced cancer stage. Two cardiovascular manifestations occur in glossopharyngeal neuralgia caused by the strong afferent stimulation activating brainstem mechanisms involved in cardiovascular regulation ${ }^{10,11}$. One efferent response is the bradycardia or even asystole demonstrated in some reported cases, probably due to vagal discharge, since it is blocked by atropine. Local infiltrations demonstrated that not only the vagus ipsilateral to the pain is activated, but rather a bilateral response occurs, leading to both atrial standstill and prolonged delayed ventricular escape ${ }^{10}$.

Separately, the afferent glossopharyngeal stimulus causes inhibition of vasomotor centers, which lead to peripheral vasodilatation and pronounced blood pressure falls, even when the heart is externally paced. Assuming there is no decline in myocardial contractility, cardiac output is diminished despite pacing, probably mainly because of peripheral pooling and decreased venous return ${ }^{10}$. Inhibition of sympathetic vasoconstrictor tone may produce those alterations, consistent with the findings of cessation of electrical activity of sympathetic nerves and suppression of neural secretion of norepinephrine during painful episodes leading to hypotension ${ }^{12,13}$.

Glossopharyngeal neuralgia secondary to recurrent malignant tumor in the neck is considered to carry a poor prognosis when compared to other causes. Intracranial division of the nerve has been advocated as the operation of choice for complete and permanent reduction of pain and cardiovascular symptoms, but this also carries considerable risk, especially in elderly patients. However, medical therapy, including high-dose carbamazepine, should be tried first, particularly in individuals who represent a high operative risk ${ }^{13,14}$.

We report a case of glossopharyngeal neuralgia with syncope that was associated with occult recurrence of neck cancer in the parapharyngeal space. The mechanism may be linked to invasion of the glossopharyngeal nerve adjacent to the internal carotid artery. In our case, carbamazepine was able to control the symptoms. Careful and repeated investigation of the parapharyngeal space should be required when a patient with previous neck malignancy presents with glossopharyngeal neuralgia with syncope.

\section{REFERENCES}

1. Headache Classification Subcommittee of the International Headache Society. International Classification of Headache Disorders, second edition. Cephalalgia 2004; 24 (Suppl 1):1-160.

2. Bruyn GW. Glossopharyngeal neuralgia. Cephalalgia 1983;3:143-157.

3. Rushton JG, Stevens C, Miller RH. Glossopharyngeal (vagoglossopharyngeal) neuralgia: a study of 217 cases. Arch Neurol 1981;38:201-205.

4. Marques PRB, Azevedo HRC Filho, Vilela LMG. Neuralgia vago-glossofaríngea sintomática: relato de dois casos. Neurobiologia 1986;49:269-282. 
5. Adriano MV, Leite ACCB, Afonso CRA, Azevedo M, Araujo AQC. Neuralgia vago-glossofaríngea com bradicardia: relato de caso. Anais do XV Congresso Brasileiro de Cefaléia, Rio de Janeiro, 2002.

6. Elias J, Kuniyoshi R, Carloni WVH, Borges MR, Peixoto CA, Pimentel D. Glossopharyngeal neuralgia associated with cardiac syncope. Arq Bras Cardiol 2002;78:515-519.

7. Nakahira M, Nakatani H, Takeda T. Syncope as a sign of occult malignant recurrence in the retropharyngeal and parapharyngeal space: CT and MR imaging findings in four cases. Am J Neuroradiol 2002;23:12571260.

8. Macdonald DR, Strong E, Nielsen S, Posner JB. Syncope from head and neck cancer. J Neurooncol 1983;1:257-267.

9. Papay FA, Roberts JK, Wegryn TL, Gordon T, Levine HL. Evaluation of syncope from head and neck cancer. Laryngoscope 1989;99:382-388.

10. Barbash GI, Keren G, Korczyn AD et al. Mechanisms of syncope in glossopharyngeal neuralgia. Electroencephalogr Clin Neurophysiol 1986;63:231-235

11. Pujadas R, Anguera N, Batalla N, Abardia J, Machengs I, Freixa E. Coexistencia de dos mecanismos hemodinámicamente significativos en el síncope asociado a neuralgia del glosofaríngeo. Rev Esp Cardiol 1990;43:408-409.

12. Wallin BG, Westerberg CE, Sundlof G. Syncope induced by glossopharyngeal neuralgia: sympathetic outflow to muscle. Neurology 1984;34:522-524.

13. Dykman TR, Montgomery EB Jr, Gerstenberger PD, Zeiger HE, Clutter WE, Cryer PE. Glossopharyngeal neuralgia with syncope secondary to tumor: treatment and pathophysiology. Am J Med 1981;71:165-168.

14. Metheetrairut C, Brown DH. Glossopharyngeal neuralgia and syncope secondary to neck malignancy. J Otolaryngol 1993;22:18-20.

15. Kollmannsberger A von, Albert HH von, Moll H. GlossopharyngicusNeuralgie als Ursache synkopaler Anfälle. Munch Med Wochenschr 1964;20:938-942.

16. Meienberg O, Glauser R, Koller H. Synkopale Anfälle bei glossopharyngikus Neuralgie. Schweiz Med Wochenschr 1975;105:1144-1147.

17. Roa NL, Krupin BR. Glossopharyngeal neuralgia with syncope - anesthetic considerations. Anesthesiology 1981;54:426-428.

18. Greenberg HS, Deck MDF, Vikram B, Chu FCH, Posner JB. Metasta- sis to the base of the skull: clinical findings in 43 patients. Neurology 1981;31:530-537.

19. Sobol SM, Wood BG, Conoyer M. Glossopharyngeal neuralgia-asystole syndrome secondary to parapharyngeal space lesions. Otolaryngol Head Neck Surg 1982;90:16-19.

20. Fleischmann H, Kriebel J, Meyer F, Lenz M. Glossopharyngicus Neuralgie mit synkopalen Anfällen bei Foramen jugulare Syndrom. Nervenarzt 1983;54:208-210.

21. Kim SS, Lal R, Ruffy R. Bradycardic and vasodepressor syncope secondary to glossopharyngeal neuralgia from hypopharyngeal tumor. Am Heart J 1985;109:1101-1102.

22. Weinstein RE, Herec D, Friedman JH. Hypotension due to glossopharyngeal neuralgia. Arch Neurol 1986;43:90-92.

23. Chalmers AC, Olson JL. Glossopharyngeal neuralgia with syncope and cervical mass. Otolaryngol Head Neck Surg 1989;100:252-255.

24. Tang $\mathrm{Y}$, Wang JM, Huang CH. Syncope in nasopharyngeal carcinoma: report of three cases and review of the literature. Changgeng Yi Xue Za Zhi 1993;16:59-65.

25. Rumoroso JR, Arana J, Montes PM, González-Liebana J, Cembellín JC, Barrenetxea JI. Síncope asociado a neuralgia del glosofaríngeo y tumoración parafaríngea. Rev Esp Cardiol 1996;49:704-706.

26. Carrat X, François JM, Houliat Th, Bertrand B, Devars F, Traissac L. Névralgie syncopale du glossopharyngien par envahissement tumoral. conduite thérapeutique. A propos de deux cas. Rev Laryngol Otol Rhinol 1996;117:137-140.

27. Nicholls S, Trim G, Hereford-Ashley P, Leitch J, Barlow M. Pain in the neck. Lancet 2003;361:1700.

28. Enguita RG, Monforte HO, Valls AR, Agraz JLG. Parada cardíaca durante intubación con fibrobroncoscopio en paciente con neoplasia del espacio parafaríngeo. Rev Esp Anestesiol Reanim 2003;50:409-413.

29. García C, Serrano S, Capellades J, Valle V. Síncope secundario a syndrome del espacio parafaríngeo con neuralgia del glosofaríngeo asociada. Med Clin (Barc) 2003;121:356.

30. Worth PF, Stevens JC, Lasri F, et al. Syncope associated with pain as the presenting feature of neck malignancy: failure of cardiac pacemaker to prevent attacks in two cases. J Neurol Neurosurg Psichiatry 2005;76:1301-1303. 